\title{
Relationships between perceived health status and ambient air quality parameters in healthy Japanese: a panel study
}

\author{
Motoyuki Nakao ${ }^{1}$, Keiko Yamauchi ${ }^{1}$, Satoshi Mitsuma ${ }^{2}$, Hisamitsu Omori ${ }^{3}$ and Yoko Ishihara ${ }^{1 *}$
}

\begin{abstract}
Background: There has been growing global concern about air pollution due to its great risk to public health. In Japan, although industrial- and traffic-related air pollution has been decreasing, concerns about particulate matter air pollution has been growing in recent years. In this study, we examined the effects of air pollution on symptoms and the health status of healthy subjects in Japan.
\end{abstract}

Methods: Participants ( $n=2887$ ) who visited healthcare centers in Kumamoto or Niigata prefectures in February from 2010 to 2015 were asked to fill out a questionnaire, which was a self-completed booklet containing questions on the characteristics of participants, their respiratory symptoms, and questionnaires on their health status in February, May, and July. Generalized estimating equation analyses were performed to predict the factors associated with the symptoms and health status using two-week averages of air quality parameters obtained from 49 monitoring stations as independent variables.

Results: Only allergy was associated with air quality in both areas. Prevalence of the other respiratory symptoms were correlated with air quality only in Kumamoto. The health statuses including the 'physical fitness', 'daily activities', and 'social activities' domains were related only to time spent outdoors. The 'overall health' was associated with time spent outdoors and concentrations of nitrogen dioxide and suspended particulate matters (SPM) in Kumamoto, and with temperatures and SPM in Niigata. The 'pain' score was correlated with temperature and carbon monoxide concentration only in Kumamoto. In Kumamoto, the 'quality of life (QoL)' was worse in those who spent shorter hours outdoors, were exposed to lower humidity, higher concentrations of oxidants, SPM, and PM2.5, and who experienced more Asian sand dust (ASD) events. In Niigata, a worsened 'QoL' was associated with time spent outdoors, temperature, and SPM.

Conclusions: The associations between air quality and the health status was found mainly in the comprehensive domain of the health status such as 'overall health' and 'QoL'. The effect of short-term exposure to larger particles, such as SPM, on health status was observed when compared to smaller particles such as PM2.5 and gaseous pollutants.

Keywords: Air pollution, Asian sand dust, Particulate matter, Health status, COOP/WONCA chart, Respiratory symptoms, Japan

\footnotetext{
*Correspondence: blackcat@med.kurume-u.ac.jp

${ }^{1}$ Department of Public Health, School of Medicine, Kurume University, 67

Asahimachi, Kurume, Fukuoka 830-0011, Japan

Full list of author information is available at the end of the article
}

(c) The Author(s). 2019 Open Access This article is distributed under the terms of the Creative Commons Attribution 4.0 International License (http://creativecommons.org/licenses/by/4.0/), which permits unrestricted use, distribution, and reproduction in any medium, provided you give appropriate credit to the original author(s) and the source, provide a link to the Creative Commons license, and indicate if changes were made. The Creative Commons Public Domain Dedication waiver (http://creativecommons.org/publicdomain/zero/1.0/) applies to the data made available in this article, unless otherwise stated. 


\section{Background}

Global concern about air pollution has been glowing due to its great risk to public health. According to World Health Organization (WHO), 6.5 million global deaths per year is estimated to be contributed to by air pollution. [1]. Air pollution levels have been increasing in developing countries, although those in affluent countries of the Americas, Europe, and Western Pacific have been decreasing. In developing countries in Asia, the burden of air pollution on has been disproportionately heavy with cardiovascular diseases and premature deaths [2]. During the 1950s to 1960s in Japan, also known as the high economic growth period, the major source of air pollution was sulfur dioxide produced from heavy industries, causing respiratory diseases such as asthma in the industrial area. Then, during the 1970s, air pollution due to motor vehicle exhaust containing nitrogen dioxide and particulate matters became a serious problem. This traffic-related air pollution was also linked to the onset and aggravation of childhood asthma in cities along major roads with heavy traffic [3]. These air pollutions have been decreasing through efforts by policymakers and public administrations through enforcement of legislation against air pollution such as the Basic Act for Environmental Pollution Control (1967) and the Air Pollution Control Act (1968) [4].

In recent years, air pollution in mainland East Asia is reported to be one of the most air-polluted areas in the world [5-7], and transboundary air pollution from mainland East China is the reason for renewed concern about air pollution in Japan $[8,9]$. Pollutants are generated by human activities such as transportation, industries, and solid fuel combustion [10]. In addition to these anthropogenic sources, natural phenomenon called Asian sand dust (ASD, also known as "yellow sand") also causes air pollution in Japan. ASD particles originating from Northeast Asia including the Gobi and Taklamakan deserts, and the Loess plateau travel long distance to Japan with the Westerlies and monsoon, and are accompanied by air pollutants produced from industrialized areas in the east coast of China [11-13]. Health effects of particulate matter air pollution have been reported through a perspective of mortality and morbidity of cardiopulmonary diseases, the prevalence of respiratory symptoms and hospital admissions [14-16]. Although the health effects of air pollution including mortality, symptoms, and physiological functions have been previously reported in Japan [17-20], the health-related quality of life (QoL), which refers to the multidimensional concept of a subjective perception of well-being, should also be used as an adverse health outcome [21]. In this study, we examined the effects of air pollution including ASD events on the symptoms and the health status of healthy subjects in two geographically distinct areas; Kumamoto in southwest Japan where air pollution is relatively high due to transboundary air pollution, and Niigata in the mid-north of Honshu island where air pollution is relatively mild.

\section{Methods}

\section{Study design and subjects}

The present studies were conducted at two healthcare centers in Japan, the Japan red cross Kumamoto healthcare center (Kumamoto prefecture) and the Niigata association of occupational health (Niigata prefecture). Participants were Japanese adults aged between 40 and 79 years, and they were recruited at the healthcare centers during their medical checkup. The questionnaires were administered to study participants in February, and the participants were followed up in May and July. The administration of the questionnaire was on site in February and by mail in May and July. The studies were started in 2010 and finished in 2015, and the participants were different each year. Subjects who agreed to participate in the present study received a self-completed questionnaire, which is the Japanese version of the questionnaire used in our previous study [22]. The questionnaire contained questions on age, gender, occupation, respiratory symptoms during last two weeks, as well as the COOP/WONCA charts (The 'Dartmouth COOP Functional Health Assessment Charts/WONCA (World organization of Family Doctors)'). The COOP/WONCA chart is valid, reliable, and easily understandable questionnaire, and widely used to measure multidimensional health status including health-related quality of life (QoL) during last two weeks. For the Japanese version of the COOP/WONCA charts, permission was obtained from the Japan Primary Care Association. The COOP/WONCA charts consists of eight items (physical fitness; feelings; daily activities; social activities; change in health; overall health; pain; QoL) [23]. Responses to these items were scored on a five-point ordinal scale ranging from 1 to 5 ( 1 = best, 5 $=$ worst $)$. At the time of administration of the first questionnaire, physician conducted body measurements, medical interviews, auscultation, and some examination as part of the medical checkup. Subjects diagnosed as severe diseases or having history of severe diseases such as cancer or pneumonectomy, who did not complete questionnaires, or did not undergo proper checkup were excluded from further analysis.

\section{Air quality data}

Air monitoring data were obtained from local public administration (Kumamoto and Niigata prefectures) and the Ministry of the Environment of Japan. Measuring method of the data including carbon monoxide, nitrogen dioxide, photochemical oxidants (oxidants), sulfur 
dioxide, particulate matter less than $2.5 \mu \mathrm{m}$ in diameter (PM2.5), suspended particulate matters (SPM) were according to the ministry of the environment of Japan [24]. SPM was defined as airborne particles with a diameter $\leq 10 \mu \mathrm{m}$ and oxidants were oxidizing substances such as ozone and peroxyacetyl nitrate produced by photochemical reactions (only those capable of isolating iodine from neutral potassium iodide, excluding nitrogen dioxide) [24]. Data obtained at the nearest monitoring station of the residential addresses of each participant was considered as the subject's environmental exposure. The map of the survey area was shown in Fig. 1. The number of monitoring stations used for exposure assessment were 26 in Kumamoto and 23 in Niigata. The distance from each participants' address were shown in Table 1.

\section{Data handling and statistical analyses}

Data obtained in this study were anonymized and administered as electronic data for the analysis. To make the scores of the COOP/WONCA charts available for generalized estimating equation (GEE) analyses, we dichotomized the COOP/WONCA chart scores as dependent variables ( 0 for better scores $(1,2$ points for the 'physical fitness' and 'feelings'; 1-3 points for the 'daily activities,' 'social activities,' 'change in health', 'overall health, 'pain', and 'QoL'); 1 for worse scores (3-5 points for the 'physical fitness' and 'feelings'; 4, 5 points for the 'daily activities', 'social activities', 'change in health', 'overall health', 'pain', and 'QoL')). Respiratory symptoms (Q1, Does the weather affect your cough?; Q2, Have you ever coughed up sputum from your chest when you do not have a cold?; Q3, Do you usually cough up sputum from your chest first thing in the morning?; Q4, How frequently do you wheeze?; Q5 Do you have or have you had any allergies? (0, No (Q1-3 and 5) or Never (Q4); 1, Yes $(\mathrm{Q} 1-3$ and 5) or Occasionally or more often $(\mathrm{Q} 4)))$ were also employed as dependent variables for GEE analysis. All odds ratios (OR) were adjusted by year of survey, age, gender, body mass index (BMI), smoking status, working status, and subsequently, parameters representing environmental exposure including time spent outdoors, ambient temperature, relative humidity, carbon monoxide, nitrogen dioxide, oxidants, sulfur dioxide, PM2.5, SPM, or number of ASD events were entered separately (see Independent variables). Statistical analyses were performed using the statistical software package SPSS ver. 22 (IBM Corporation, Armonk, NY, USA). $P$ values of less than 0.05 were considered statistically significant.

\section{Independent variables}

For GEE analysis, ORs were adjusted by the independent variables including year of survey (2010-2015), age (years old), gender ( 0 , female; 1 , male), BMI $\left(\mathrm{kg} / \mathrm{m}^{2}\right)$, current smoking status ( 0 , non-smoker; 1 ex-smoker; 2 , current smoker), and working status ( 0 , currently working; 1, retired or not in employment). For the parameters regarding exposure to ambient air, the ORs were presented as incremental difference of one hour spent outdoors, $10{ }^{\circ} \mathrm{C}$ of ambient temperature, $10 \%$ of relative humidity, one ASD event, $10 \mathrm{ppb}$ of carbon monoxide, nitrogen dioxide, oxidants, and sulfur dioxide, and $10 \mu \mathrm{g} / \mathrm{m}^{3}$ of PM2.5 and SPM. For carbon monoxide, nitrogen dioxide, sulfur dioxide, PM2.5, and SPM, the mean of the preceding 14 daily mean values was entered as the independent variable. The mean of the preceding 14 mean values from $6 \mathrm{am}$ to $8 \mathrm{pm}$ of each day was entered as the independent variable of oxidants. For ASD events, the number of ASD events in the month prior to each survey was entered as the independent variable. All independent variables except for air quality data were included in each model. Air quality variables were entered separately because these air quality parameters vary in relation to each other.

\section{Results}

\section{Participant characteristics}

Table 1 shows the participants' characteristics. During the month of February from 2010 to 2015, a total of 1537 and 1350 subjects in Kumamoto and Niigata prefectures, respectively, participated in this study. The overall follow-up rate was higher in Niigata prefecture than that in Kumamoto prefecture. Male participants were more than twice as much as female participants in both regions. The percentage of active worker was higher in Niigata prefecture than that in Kumamoto prefecture, reflecting the younger mean age of participants in Niigata prefecture when compared to that in Kumamoto prefecture. Current smoking rate in Niigata prefecture was nearly twice of that in Kumamoto prefecture. The prevalence of symptoms were similar between Kumamoto and Niigata prefecture.

\section{Seasonal variations of ambient air quality during the present study}

The monthly mean of all available air quality data during January to July is presented in Fig. 2. The temperature in Kumamoto was generally higher than in Nigata. Relative humidity was relatively higher in June and July during the rainy season in both areas. Carbon monoxide and sulfur dioxide concentrations were higher in Kumamoto than in Niigata, and the concentrations were higher in the winter months than in the spring and summer. Additionally, these concentrations were well below air quality standard (AQS) in Japan. Oxidant concentration in Kumamoto was comparable with that of Niigata, and these levels tended to be high during March to May in 


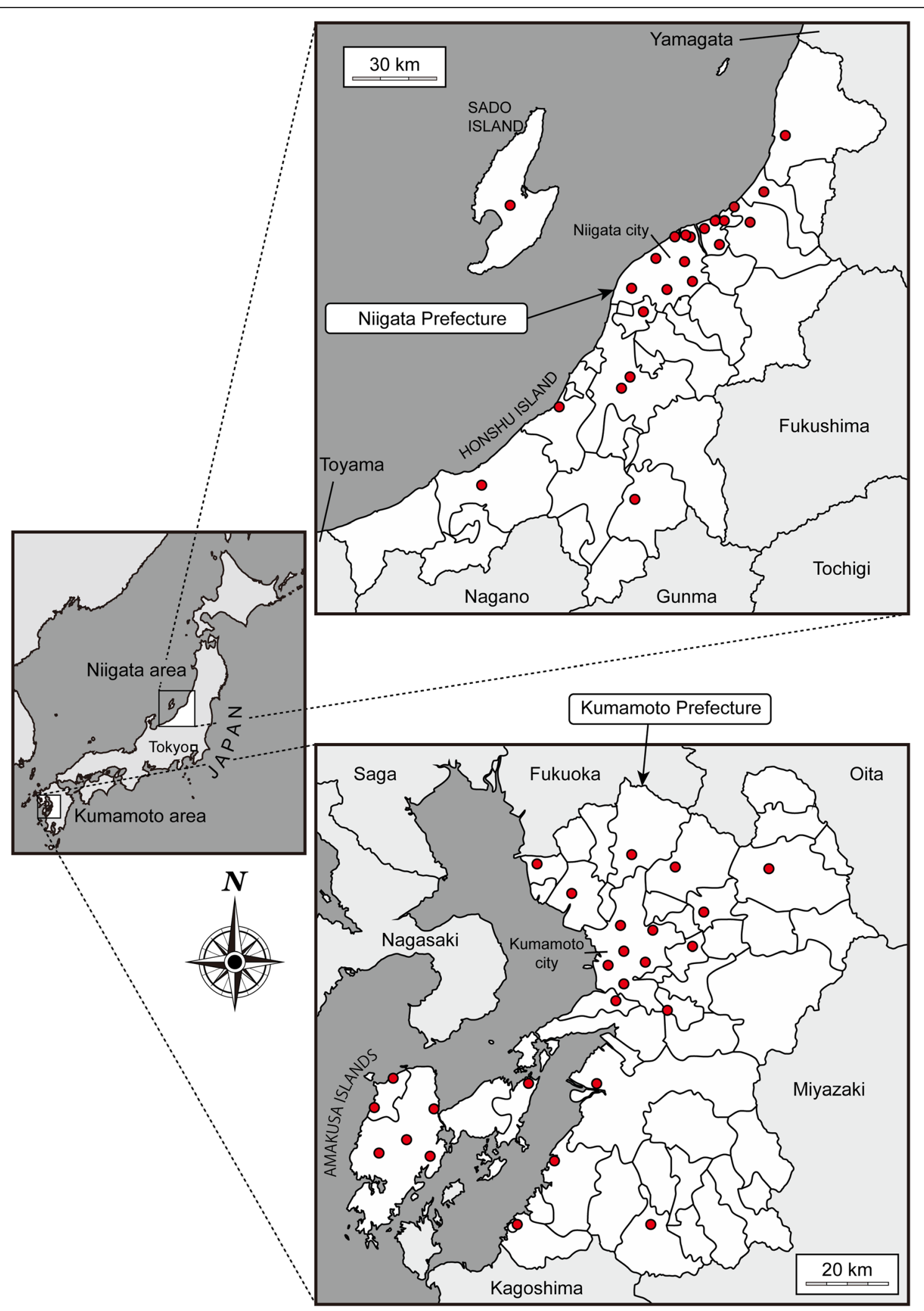

Fig. 1 Study area and the location of monitoring stations. Left panel shows map of Japan. Niigata and Kumamoto prefecture were shown in the right-upper panel and right-lower panel, respectively. Monitoring stations were presented as red circles. The original data of the map was obtained from http://d-maps.com/index.php?lang=en 
Table 1 Characteristics of participants

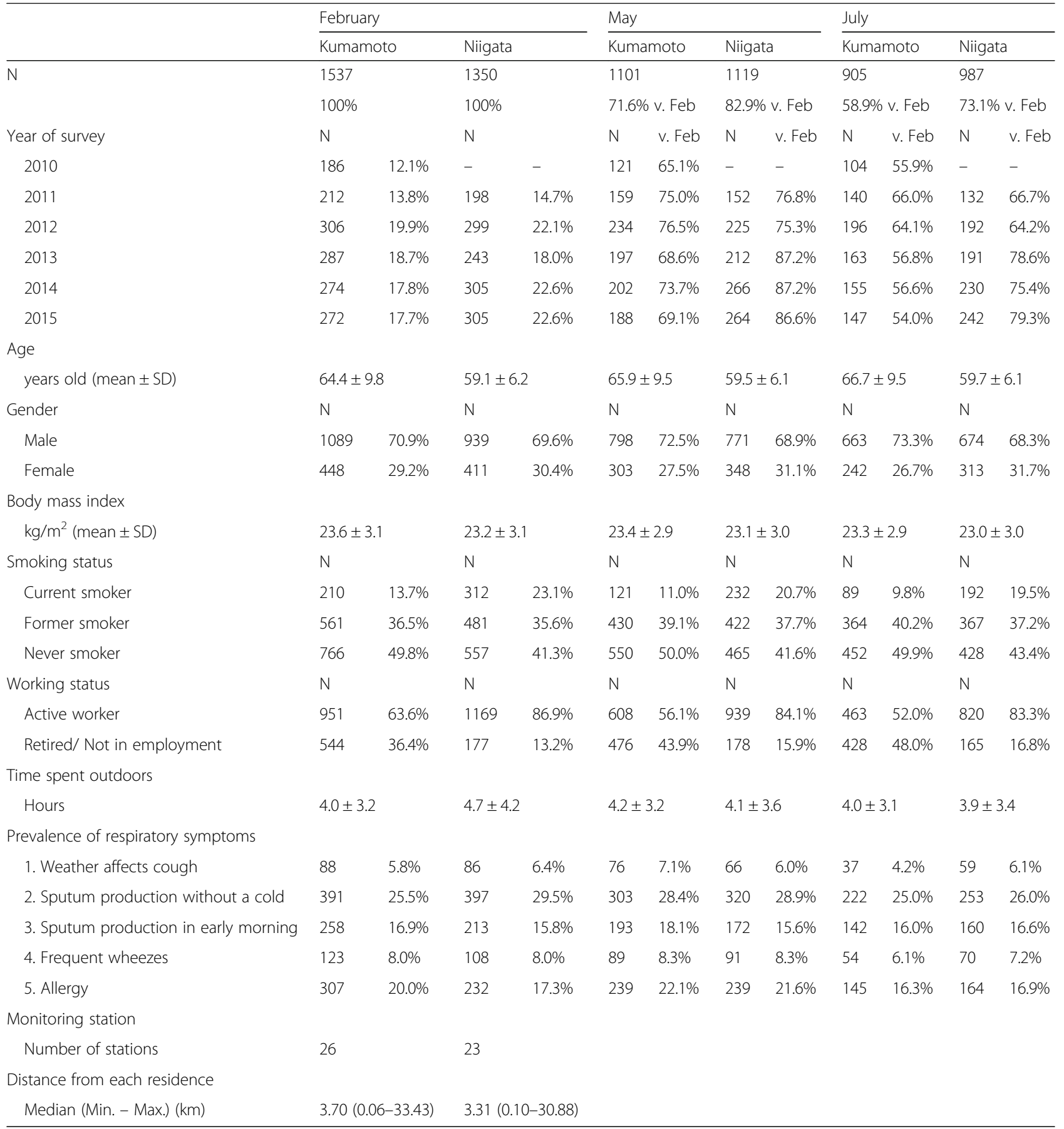

both areas. Although the monthly average of the daily mean oxidant levels did not reach AQS, there were many days that the hourly oxidant level during daytime (from 6 am to $8 \mathrm{pm}$ ) exceeded AQS. Nitrogen dioxide concentrations tended to be higher in Niigata compared to Kumamoto, and was high in the winter months and gradually decreased in the following months. Additionally, these concentrations were well below AQS in Japan. Monthly mean PM2.5 levels were relatively higher in Kumamoto than in Niigata, although there were large fluctuations in the intra-month levels in both areas. This fluctuation was also observed for SPM levels. There were several days that the daily PM2.5 and SPM levels exceeded AQS while the monthly means of both were below AQS. There were more ASD events in Kumamoto than in Niigata every year and almost all events occurred during springtime. The total number of ASD events was 39 in Kumamoto during 2010-2015 and 12 in Niigata during 2011-2015. 


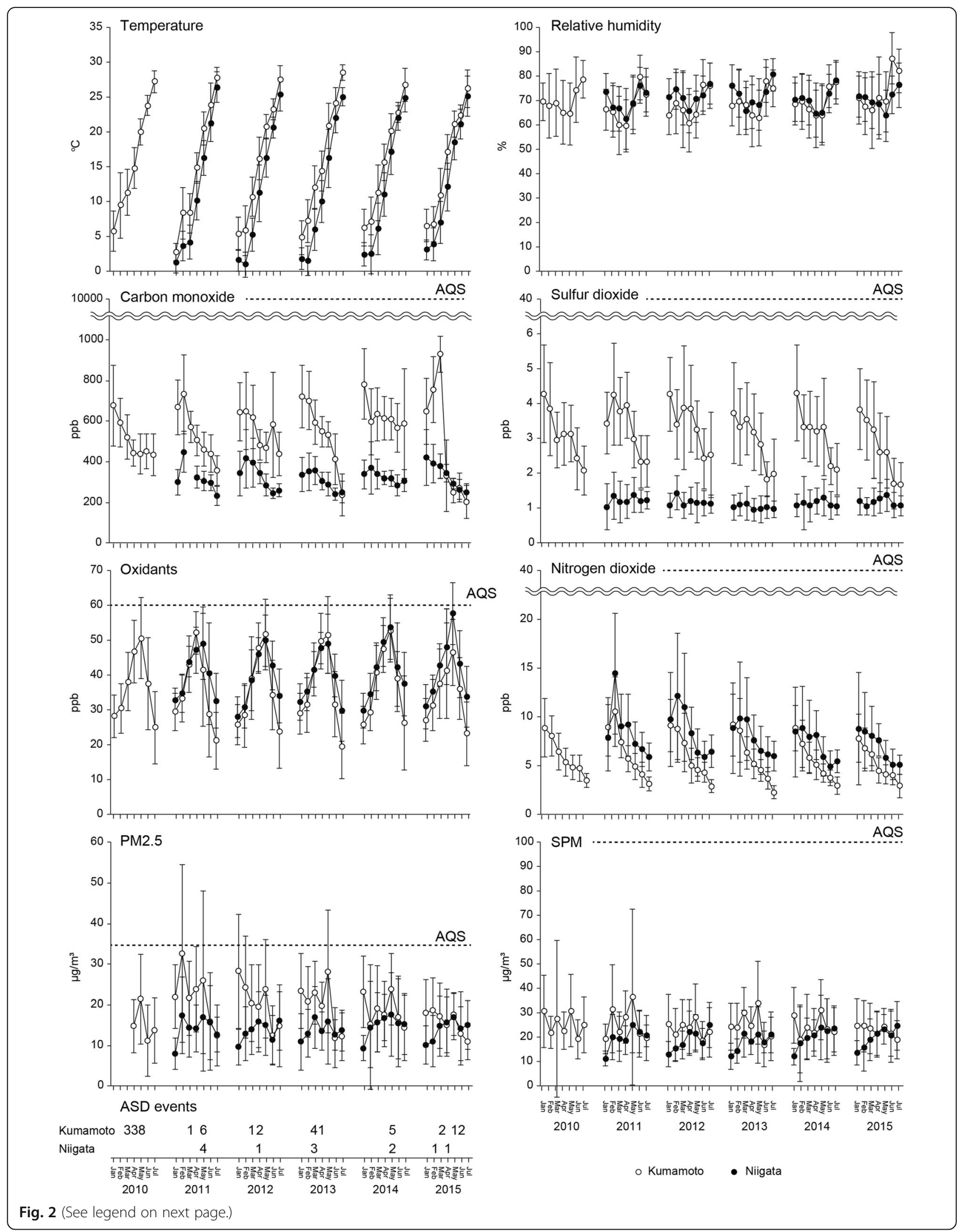


(See figure on previous page.)

Fig. 2 Temporal variations of air quality parameters during January 2010 - July 2015. The monthly averages of the daily mean values of temperature, relative humidity, the concentrations of carbon monoxide, nitrogen dioxide, oxidants, sulfur dioxide, PM2.5, and SPM, and the number of ASD events per month. Data were collected from the ministry of environment of Japan and all the monitoring stations from which data were available. Data except for the number of ASD events were presented as mean \pm SD. Open circles and closed circles represent the data in Kumamoto and Niigata, respectively. The national ambient AQS is shown as a dotted line

\section{Association of ambient air pollutant exposure with subjective respiratory symptoms}

GEE analysis was used to identify the association between variables regarding air pollution and respiratory symptoms (Table 2). In Kumamoto prefecture, symptom 1 (weather affects a cough) was positively associated with the concentrations of oxidants, SPM, and PM2.5, and the number of ASD events. Symptom 2 (sputum production without a cold) was increased in association with the concentrations of oxidants, SPM, and PM2.5. Symptoms 1, 3 (sputum production first thing in the morning), 4 (frequent wheezes), and 5 (allergy) were negatively associated with an increment in relative humidity and positively associated with oxidants concentration. Additionally, symptom 5 was positively correlated with SPM and PM2.5 concentrations. In Niigata, only symptom 5 was significantly associated with a shorter time spent outdoors, lower relative humidity, higher concentrations of carbon monoxide, oxidants, and SPM, and ASD events.

\section{Association of ambient air pollutant exposure with health} status measured by the COOP/WONCA chart

GEE analysis was also used to identify the association between variables regarding air pollution and the health status measured by the COOP/WONCA chart (Table 3). Shorter hours spent outdoors was associated with worse

Table 2 Associations between variables regarding ambient air pollutant exposure and respiratory symptoms

\begin{tabular}{|c|c|c|c|c|c|c|c|c|c|c|}
\hline \multirow[b]{3}{*}{ Independent variables } & \multicolumn{10}{|c|}{ Dependent variables (0, no symptom; 1 , having symptom) } \\
\hline & \multicolumn{2}{|c|}{ Symptom 1} & \multicolumn{2}{|c|}{ Symptom 2} & \multicolumn{2}{|c|}{ Symptom 3} & \multicolumn{2}{|c|}{ Symptom 4} & \multicolumn{2}{|c|}{ Symptom 5} \\
\hline & $\overline{\mathrm{OR}}$ & $95 \% \mathrm{Cl}$ & $\overline{\mathrm{OR}}$ & $95 \% \mathrm{Cl}$ & $\overline{\mathrm{OR}}$ & $95 \% \mathrm{Cl}$ & $\overline{\mathrm{OR}}$ & $95 \% \mathrm{Cl}$ & $\overline{\mathrm{OR}}$ & $95 \% \mathrm{Cl}$ \\
\hline \multicolumn{11}{|l|}{ Kumamoto } \\
\hline Hours spent outdoors (each 1 h) & 1.01 & $0.96-1.07$ & 0.97 & $0.94-1.01$ & 0.97 & $0.93-101$ & 1.01 & $0.97-1.07$ & 0.99 & $0.95-1.03$ \\
\hline Temperature (each $\left.10^{\circ} \mathrm{C}\right)$ & 0.93 & $0.79-1.09$ & 1.05 & $0.97-1.14$ & 0.98 & $0.89-1.07$ & 0.92 & $0.79-1.06$ & 0.95 & $0.88-1.04$ \\
\hline Relative humidity (each 10\%) & 0.78 & $0.67-0.90$ & 0.95 & $0.89-1.02$ & 0.94 & $0.73-0.96$ & 0.84 & $0.73-0.96$ & 0.86 & $0.79-0.93$ \\
\hline Carbon monoxide (each 10 ppb) & 1.00 & $0.99-1.01$ & 1.00 & $1.00-1.00$ & 1.00 & $1.00-1.01$ & 1.00 & $1.00-1.01$ & 1.00 & $1.00-1.01$ \\
\hline Nitrogen dioxide (each 10 ppb) & 1.08 & $0.83-1.44$ & 1.01 & $0.87-1.17$ & 1.15 & $0.97-1.37$ & 1.18 & $0.93-1.49$ & 1.12 & $0.94-1.31$ \\
\hline Oxidants (each 10 ppb) & 1.16 & $1.06-1.27$ & 1.06 & $1.01-1.12$ & 1.03 & $0.98-1.09$ & 1.10 & $1.02-1.20$ & 1.10 & $1.04-1.16$ \\
\hline Sulfur dioxide (each 10 ppb) & 0.65 & $0.21-2.00$ & 0.34 & $0.17-0.67$ & 0.57 & $0.24-1.33$ & 0.61 & $0.16-2.22$ & 1.45 & $0.71-2.97$ \\
\hline SPM (each $10 \mu \mathrm{g} / \mathrm{m}^{3}$ ) & 1.17 & $1.02-1.34$ & 1.10 & $1.02-1.20$ & 1.08 & $0.99-1.18$ & 1.07 & $0.95-1.21$ & 1.15 & $1.06-1.26$ \\
\hline PM2.5 (each $10 \mu \mathrm{g} / \mathrm{m}^{3}$ ) & 1.17 & $1.03-1.33$ & 1.17 & $1.03-1.33$ & 1.10 & $0.96-1.27$ & 1.18 & $0.94-1.49$ & 1.32 & $1.15-1.52$ \\
\hline Asian sand dust event (each 1 event in last one month) & 1.11 & $1.05-1.17$ & 1.03 & $1.00-1.05$ & 0.99 & $0.96-1.02$ & 1.03 & $0.98-1.09$ & 1.03 & $1.00-1.07$ \\
\hline \multicolumn{11}{|l|}{ Niigata } \\
\hline Hours spent outdoors (each 1 h) & 1.01 & $0.97-1.06$ & 1.00 & $0.97-1.03$ & 0.99 & $0.96-1.03$ & 1.02 & $0.98-1.06$ & 0.96 & $0.93-0.99$ \\
\hline Temperature (each $10^{\circ} \mathrm{C}$ ) & 0.98 & $0.84-1.14$ & 0.93 & $0.87-1.00$ & 1.04 & $0.95-1.14$ & 0.98 & $0.85-1.12$ & 1.02 & $0.94-1.09$ \\
\hline Relative humidity (each 10\%) & 1.08 & $0.83-1.42$ & 0.90 & $0.79-1.03$ & 1.13 & $0.97-1.32$ & 0.97 & $0.74-1.27$ & 0.71 & $0.61-0.83$ \\
\hline Carbon monoxide (each 10 ppb) & 1.01 & $0.98-1.04$ & 1.00 & $0.98-1.02$ & 0.99 & $0.97-1.01$ & 0.99 & $0.97-1.02$ & 1.02 & $1.00-1.04$ \\
\hline Nitrogen dioxide (each 10 ppb) & 0.73 & $0.46-1.17$ & 0.93 & $0.72-1.21$ & 0.96 & $0.69-1.32$ & 0.83 & $0.55-1.22$ & 1.03 & $0.78-1.38$ \\
\hline Oxidants (each 10 ppb) & 0.96 & $0.87-1.06$ & 1.02 & $0.97-1.07$ & 0.98 & $0.92-1.04$ & 1.03 & $0.94-1.14$ & 1.14 & $1.07-1.21$ \\
\hline Sulfur dioxide (each 10 ppb) & 1.93 & $0.09-45.52$ & 0.95 & $0.15-5.89$ & 0.51 & $0.05-5.69$ & 1.02 & $0.05-21.65$ & 2.26 & $0.30-17.19$ \\
\hline SPM (each $10 \mu \mathrm{g} / \mathrm{m}^{3}$ ) & 0.96 & $0.78-1.18$ & 0.93 & $0.83-1.04$ & 0.97 & $0.84-1.12$ & 0.93 & $0.77-1.12$ & 1.16 & $1.02-1.32$ \\
\hline PM2.5 (each $10 \mu \mathrm{g} / \mathrm{m}^{3}$ ) & 0.90 & $0.63-1.31$ & 0.94 & $0.77-1.15$ & 0.94 & $0.72-1.23$ & 0.95 & $0.66-1.36$ & 1.20 & $0.96-1.49$ \\
\hline Asian sand dust event (each 1 event in last one month) & 0.98 & $0.87-1.11$ & 0.98 & $0.92-1.04$ & 1.01 & $0.93-1.09$ & 1.08 & $0.97-1.19$ & 1.10 & $1.03-1.18$ \\
\hline
\end{tabular}

Symptom 1, weather affects a cough; symptom 2, coughing up sputum when the subject does not have a cold; symptom 3 , coughing up sputum first thing in the morning; symptom 4, frequent wheeze; symptom 5, allergic symptoms. Odds ratios (OR) were adjusted by year of survey, gender, age, body mass index (kg/m ${ }^{2}$ ), smoking status (current, former, or never smoker), working status (active worker or retired/ not in employment). Cl, confidence interval; ppb, part per billion; SPM, Suspended particulate matter; PM2.5, Particulate matter less than $2.5 \mu \mathrm{m}$ in diameter 





scores for 'physical fitness', 'daily activities,' 'social activities,' 'overall health', and 'QoL' items in Kumamoto, and for 'physical fitness', 'social activities', and 'quality of life' items in Niigata. Regarding ambient temperature, only the 'pain' item was negatively associated in Kumamoto, while it was positively associated with 'overall health' and 'QoL' items in Niigata. In Kumamoto, relative humidity was negatively correlated only with the 'QoL' item, higher carbon monoxide concentration was only associated with a worse score for the 'pain' item, higher nitrogen dioxide and SPM concentrations were associated with the 'overall health' item, and SPM also associated with a worse score for the 'QoL' item. The 'QoL' item was also associated with PM2.5 concentration and number of ASD events in Kumamoto. In Niigata, higher SPM concentration was associated with a worse score for 'overall health' and 'QoL' items.

\section{Discussion}

We carried out a health survey on 2887 Japanese middle-aged or elderly subjects who visited a healthcare center for a medical checkup in Kumamoto and Niigata prefectures during 2010-2015, and the participants were different for each year. The survey was a three time-point questionnaire survey. The first survey was held in February when air pollution is relatively severe. The participants were followed up in May when ASD events have been frequently observed in the Western part of Japan. The last survey was held in July when the ambient air is the cleanest. A GEE approach was applied to identify the environmental factors associated with subjects' respiratory symptoms and the health status as measured by the COOP/WONCA chart. The association of air quality parameters with respiratory symptoms and several aspects of the health status were found in both areas.

Health effects of ambient air pollution have been reported several decades ago. In particular, the Great Smog of London of December 1952 is a well-known episode of acute exposure to lethal smog [25]. Air pollutants such as sulfur dioxide derived from coal-burning homes, coal-fired power plants, and factories caused heavy smog under the condition of temperature inversion due to windless cold weather [26]. This episode resulted in thousands of excessive death and sickness. Since then, numerous studies regarding the effect of air pollution on health such as cardiopulmonary mortality and morbidity has been published [16, 27]. In the present study, in Kumamoto, increased concentrations of oxidants, SPM, and PM2.5 were associated with symptoms 1 (weather affects a cough), 2 (sputum production without a cold), and 5 (allergy) (Table 2). Symptoms 1 and 5 were also related to the number of ASD events and lower relative humidity, respectively. Symptom 3 (sputum production first thing in the morning) was negatively associated with relative humidity. Symptom 4 (frequent wheezes) was increased in association with higher oxidant concentration and lower humidity. In contrast to Kumamoto, only symptom 5 was associated with parameters regarding ambient air pollution exposure in Niigata. Symptom 5 (Allergy) was the most sensitive to humidity levels and air pollutants in both areas. In some cases of environmental exposure, allergic or asthma-like symptoms has been reported to occur without clinical signs [28]. It is, therefore, unsurprising that the healthy subjects in this study presented with these respiratory symptoms. The monthly averages of the daily mean ambient temperature, relative humidity, and air pollutant concentrations were calculated and are shown in Fig. 2, and the air pollutant concentrations were generally lower in Niigata than those in Kumamoto with a few exceptions. It is suggested to be the reason that the associations between air pollution and respiratory symptoms were weaker in Niigata than in $\mathrm{Ku}$ mamoto. In the present study, presentation of allergic symptoms might have a lower threshold for environment exposure compared with other symptoms as it was the symptom most widely associated with the environment in both regions. Oxidant concentration was significantly associated with four kinds of symptoms in Kumamoto. Adverse health effects of ozone ranging from respiratory symptoms to increased mortality have been well-documented [29, 30]. Exposure to ozone has been reported to enhance airway hyperreactivity at frequently observed concentrations even in healthy subjects $[31,32]$. The result of the present study was consistent with these previous studies. Particulate matters were associated with cough, sputum, and allergic symptoms in Kumamoto, and to allergic symptom in Niigata (Table 2). Health effects of acute exposure to particulate matter air pollution have widely been evaluated using end points such as death, cardiovascular mortality, hospitalization, healthcare visit, lung function, and respiratory symptoms [14-16, 33]. In addition to the anthropogenic origin of air pollution, ASD events also have a great influence on the particulate matter concentration in East Asia including Japan [11-13]. ASD events were reported to be associated with increased cardiopulmonary mortality and morbidity in Japan [34-39]. An increased number of ASD events was significantly associated with symptom 1 in Kumamoto and symptom 5 in Niigata (Table 2). In Kumamoto, the number of ASD events also showed positive association with Symptoms 2 and 5 with ORs of 1.03 (95\% confidence interval (CI): 1.00-1.05, not significant) and 1.03 (1.00-1.07, not significant), respectively. Most existing reports regarding the health effects of air pollution have been focused on children or patients with cardiopulmonary diseases because adverse effects were likely to be more obvious in these subjects. All the subjects who participated in the present study were adults and did not suffer from any chronic cardiorespiratory diseases. 
These results suggest that there are apparent associations between air pollution and respiratory symptoms even in healthy adult subjects.

According to the ATS statement, the concept of health-related QoL, which refers to the individual's perception of well-being, should also be considered as an adverse health outcome of air pollution together with mortality, clinical outcomes, physiological impact, biomarkers, and symptoms [21]. In the present study, we administered the COOP/WONCA chart to measure the health status including the QoL domain. Subjects who spent shorter hours outdoors were associated with decreased scores of 'physical fitness', 'social activities', and 'QoL' domains both in Kumamoto and Niigata (Table 3). This result suggests that those who spent longer hours outdoors lived more fulfilling lives than those who were more likely to stay indoors. A lower temperature was related to the worse score for 'pain' in Kumamoto while worse scores for 'overall health' and 'QoL' were decreased in association with higher temperature in Niigata (Table 3). Humidity was associated with the 'QoL' score only in Kumamoto. Both higher and lower ambient temperatures were reported to have adverse effects on the risk of cardiovascular diseases [40, 41]. For physical activity, a study in Japan showed that the daily step count peaks at the ambient temperature of $17^{\circ} \mathrm{C}$, while physical activity decreased at higher or lower temperatures [42]. In contrast, Giorgini et al., reported that a higher temperature was associated with a decrease in aerobic exercise capacity, leading to a worse QoL in patients undergoing cardiac rehabilitation [43]. The result in Niigata from the present study was consistent with this report, suggesting that higher ambient temperature is associated with a detrimental change in the 'overall health', and 'QoL' even in healthy subjects. In parallel, the low temperature was reported to have a significant impact on subjective pain score in a remarkable proportion of the population $[44,45]$, which is also consistent with our result in Kumamoto. Regarding meteorological conditions, further research is needed to verify the relationships between the health status and the climate parameters including rainfall, barometric variation, and abrupt weather changes. Although of a weaker association, higher carbon monoxide concentration was significantly associated with a worse score for the 'pain' scale in Kumamoto (Table 3). Higher nitrogen dioxide concentration was related to a decreased 'overall health' score, and higher PM2.5 concentration and increased number of ASD events were associated with a worse score for the 'QoL' in Kumamoto. Increased concentration of SPM was associated with worse scores for the 'overall health' and 'QoL' in both areas. Two Japanese studies showed that the concentrations of nitrogen dioxide and oxidants were significantly associated with the 'vitality' domain of the Medical Outcome Study Short Form-36 Health Survey (SF-36) $[46,47]$. The 'vitality' domain is a constituent of the mental component score of the SF-36, while the corresponding mental component in the present study is the "feelings" scale. In contrast to the previous studies, exposure to air pollution in healthy subjects in this study was not significantly associated with the 'feelings' scale, but was instead associated predominantly with comprehensive domains such as 'overall health' and 'QoL'. This difference between studies might be attributed to differences in the study population, study design, questionnaire, or analytical method. These results suggested that further studies with a consistent design is needed to clarify the exact effects of air pollution and their magnitude. The relationships between the environmental exposure and the health status were area dependent (Table $3)$. Concentrations of carbon monoxide and nitrogen dioxide were both higher in Kumamoto than in Niigata (Fig. 2), suggesting that high concentrations of these pollutants resulted in significant associations with 'pain' or 'overall health' only in Kumamoto. The associations of 'QoL' with PM2.5 concentration and the number of ASD events were significant only in Kumamoto (Table 3). High concentration of PM2.5 in Kumamoto was suggested to be transboundary air pollution from mainland Asia $[8,9]$ because Kumamoto is located in Western Japan, leeward of Westerlies. For the same reason, ASD events were observed more frequently in Kumamoto than in Niigata (Fig. 2). The frequent air pollution episodes and higher pollutant concentrations were suggested to lead to a significant association between the health status and pollution only in Kumamoto. SPM concentration showed significant relationships with 'overall health' and 'QoL' items in Kumamoto and Niigata (Table 3). This result suggests that individuals exposed to SPM might be prone to perceived decreased health status although the monthly average of the daily mean concentration of SPM was well below the AQS in both areas (Fig. 2).

There are several limitations in this study. First, due to the study design as a panel study, the participants of the present study were not strictly followed. Although more information was obtained when compared with a cross-sectional study, the causal relationship between health status and parameters regarding exposure to ambient air, remains unclear. Second, we adjusted some sociodemographic factors such as age, gender, and working status to estimate the association of environmental exposure with the symptom and health status. As we carried out the present study in two distant locations of which subject and geographical characteristics were very different, the possibilities of the existence of the unknown unadjusted confounders cannot be 
excluded. Third, although air quality data were obtained from the monitoring stations which were located at the nearest address of each participant, it was impossible to verify the consistency between the range of movement of each participant and the location of the monitoring station. To estimate the accurate relationship between health status and ambient air pollution exposure, it is necessary to measure indoor air quality and personal exposure to air pollution. To the respect of indoor air quality, environmental tobacco smoke or secondhand smoking at home might be used as a proxy for indoor air pollution although the information about passive smoking was not collected in the present study.

\section{Conclusions}

The associations between air quality and perceived health status were found mainly in the comprehensive domain of the health status such as "overall health" and "QoL". From the results of the present study, we speculate that the significant effects of short-term exposure to relatively large particulate matter such as SPM on health status was more readily observed when compared with the smaller particles such as PM2.5 and gaseous pollutants.

\section{Abbreviations}

AQS: Air quality standard; ASD: Asian sand dust; BMl: Body mass index; Cl: Confidence interval; GEE: Generalized estimating equation; OR: Odds ratio; PM2.5: Particulate matters less than $2.5 \mu \mathrm{m}$ in a diameter; QoL: Quality of life; SD: Standard deviation; SPM: Suspended particulate matters; WHO: World Health Organization

\section{Acknowledgements}

We would like to thank all staff at Japan Red Cross Kumamoto Health Care Center and Niigata Association of Occupational Health Inc. for their cooperation during our study. We also thank Dr. Go Hasegawa, Ms. Tomoe Terasaki and Ms. Ayumi Narumi of Kurume University.

\section{Funding}

This study was supported in part by Grants-in-Aid for Scientific Research (B) 20406001, 23406001 and (C) 26340053, and a "MEXT-Supported Program for the Strategic Research Foundation at Private Universities" from the Ministry of Education, Culture, Sports, Science and Technology, Japan in the design of the study and collection, analysis, and interpretation of data and in writing the manuscript.

\section{Availability of data and materials}

The datasets analyzed during the current study are not publicly available due to our privacy policy and agreement with participants but are available from the corresponding author on reasonable request.

\section{Authors' contributions}

MN was an associate professor at Kurume University and was involved in the literature search, data collection, data editing, analysis, interpretation, and preparing manuscript. He took the lead in developing this manuscript. KY was an advisor and was involved in the literature search and data collection. $\mathrm{SM}$ and $\mathrm{HO}$ were involved in the data collection in Niigata and Kumamoto area, respectively. They also participated in data interpretation, and provided discussion and advice in preparing the manuscript. YI was involved in the literature search; data collection, editing, analysis, and interpretation; provided discussion and advice; helped with manuscript preparation; and participated in the development of the study proposal. She also supervised all aspects of this study. All authors read and approved the final manuscript.

\section{Ethics approval and consent to participate}

This study was approved by the Clinical Ethical Review Board of Kurume University School of Medicine. Before investigation, the participants were provided with an explanation in person regarding the purpose and method of the study, as well as information regarding the handling of the results. The study was carried out upon receipt of written consent.

\section{Consent for publication}

Not Applicable.

\section{Competing interests}

Authors declare that they have no competing interests.

\section{Publisher's Note}

Springer Nature remains neutral with regard to jurisdictional claims in published maps and institutional affiliations.

\section{Author details}

${ }^{1}$ Department of Public Health, School of Medicine, Kurume University, 67 Asahimachi, Kurume, Fukuoka 830-0011, Japan. ${ }^{2}$ Niigata Association of Occupational Health Inc, Niigata, Japan. ${ }^{3}$ Department of Biomedical Laboratory Sciences, Faculty of Life Sciences, Kumamoto University, Kumamoto, Japan.

Received: 28 December 2017 Accepted: 2 May 2019

Published online: 22 May 2019

\section{References}

1. A global health guardian: Climate change, air pollution and antimicrobial resistance in ten years in public health 2007-2017: report by Dr. Margaret Chan, director-general. World Health Organization. Geneva: World Health Organization; 2017. http://www.who.int/publications/10-year-review/en/ (Accessed on 1 Nov. 2017)

2. Ambient (outdoor) air quality and health. World Health Organization. Geneva. World Health Organization; 2017. http://www.who.int/mediacentre/ factsheets/fs313/en/ (Accessed on 1 Nov. 2017).

3. Shima M, Nitta Y, Adachi M. Traffic-related air pollution and respiratory symptoms in children living along trunk roads in Chiba prefecture, Japan. J Epidemiol. 2003;13:108-19.

4. Shima M. Health effects of air pollution: a historical review and present status. Jpn J Hyg. 2017;72:159-65.

5. World Health Organization. Country profile of environmental burden of disease: China http://www.who.int/quantifying_ehimpacts/national/ countryprofile/china.pdf?ua $=1$ (Accessed on 11 Nov 2017).

6. Jin $\mathrm{Y}$, Andersson $\mathrm{H}$, Zhang S. Air pollution control policies in China: a retrospective and prospects. Int J Environ Res Public Health. 2016;13:1219.

7. He MZ, Zeng X, Zhang K, Kinney PL. Fine particulate matter concentrations in urban Chinese cities, 2005 - 2016: a systematic review. Int J Environ Res Public Health. 2017:14:191.

8. Sato K, Takami A, irei S, Miyoshi T, Ogawa Y, Yoshino A, Nakayama H, Maeda M, Hatakeyama S, Hara K, Hayashi M, Kaneyasu N. Transported and local organic aerosols over Fukuoka, Japan. Aerosol Air Qual Res. 2013;13:1263-72.

9. Moreno T, Kojima T, Querol X, Alastuey A, Amato F, Gibbons W. Natural versus anthropogenic inhalable aerosol chemistry of transboundary east Asian atmospheric outflows into western Japan. Sci Total Environ. 2012:424:182-92.

10. Gautam S, Yadav A, Tsai CJ. Kumar P. a review on recent progress in observations, sources, classification and regulations of PM2.5 in Asian environments. Environ Sci Pollut Res. 2016:23:21165-75.

11. Uno I, Amano H, Emori S, Kinoshita K, Matsui I, Sugimoto N. Trans-pacific yellow sand transport observed in April 1998: a numerical simulation. J Geophys Res. 2001;106(D16):18331-44.

12. Coulibaly S, Minami H, Abe M, Hasei T, Oro T, Funasaka K, Asakawa D, Watanabe M, Honda N, Wakabayashi K, Watanabe T. Long-range transport of mutagens and other air pollutants from mainland East Asia to Western Japan. Genes Environ. 2015:37:25.

13. Mori I, Nishikawa M, Tanimura T, Quan H. Change in size distribution and chemical composition of kosa (Asian dust) aerosol during long-range transport. Atmos Environ. 2003;37:4253-63. 
14. Klemn RJ, Mason R. Replication of reanalysis of Harvard six-city mortality study. Revised analysis of time-series studies of air pollution and health. Special report. HEl report. Boston: Health Effects Institute; 2003. p. 165-72.

15. Burnett RT, Goldberg MS. Size-fractionated particulate mass and daily mortality in eight Canadian cities. Revised analysis of time-series studies of air pollution and health. Special report. HEl report. Boston: Health Effects Institute; 2003. p. 85-9.

16. Pope CA III. Epidemiology of fine particulate air pollution and human health: biologic mechanisms and who's at risk? Environ Health Perspect. 2000;108(suppl. 4):713-23.

17. Iwai K, Mizuno S, Miyasaka Y, Mori T. Correlation between suspended particles in the environmental air and causes of disease among inhabitants: cross-sectional studies using the vital statistics and air pollution data in Japan. Environ Res. 2005;99(1):106-17.

18. Katanoda K, Sobue T, Satoh H, Tajima K, Suzuki T, Nakatsuka H, Takezaki T, Nakayama T, Nitta H, Tanabe K, Tominaga S. An association between longterm exposure to ambient air pollution and mortality from lung cancer and respiratory diseases in Japan. J Epidemiol. 2011;21(2):132-43.

19. Yamazaki S, Shima M, Yoda Y, Oka K, Kurosaka F, Shimizu S, Takahashi H, Nakatani Y, Nishikawa J, Fujiwara K, Mizumori Y, Mogami A, Yamada T, Yamamoto N. Association between PM2.5 and primary care visits due to asthma attack in Japan: relation to Beijing's air pollution episode in January 2013. Environ Health Prev Med. 2014;19:172-6.

20. Yanagita Y, Senjyu H, Asai M, Tanaka T, Yano Y, Miyamoto N, Nishinakagawa T, Kotani K, Kozu R, Tabusadani M, Honda S. Air pollution irreversibly impairs lung function: a twenty-year follow-up of officially acknowledged victims in Japan. Tohoku J Exp Med. 2013;230:177-84.

21. American Thoracic Society. What constituents an adverse health effect of air pollution? Official statement of the American Thoracic Society. Am J Respir Crit Care Med. 2000;161:665-73.

22. Nakao M, Yamauchi $K$, Ishihara Y, Solongo B, Ichinnorov D, Breugelmans R. Validation of the Mongolian version of the SF-36v2 questionnaire for health status assessment of Mongolian adults. Springerplus. 2016;5:607.

23. van Weel C. Functional status in primary care: COOP/WONCA charts. Disabil Rehabil. 1993;15(2):96-101.

24. Environmental Quality Standards in Japan - Air quality. Ministry of the Environment, Government of Japan (http://www.env.go.jp/en/air/aq/aq.html) Accessed 12 Jun 2018

25. Wilkins ET. Air pollution and the London fog of December, 1952. J R Sanit Inst. 1954;74(1):1-15.

26. Bell ML, Davis DL. Reassessment of the lethal London fog of 1952: novel indicators of acute and chronic consequences of acute exposure to air pollution. Environ Health Perspect. 2001;109(suppl 3):389-94.

27. Atkinson RW, Kang S, Anderson HR, Mills IC, Walton HA. Epidemiological time series studies of PM2.5 and daily mortality and hospital admissions: a systematic review and meta-analysis. Thorax. 2014;69(7):660-5.

28. Claeson AS, Palquist E, Lind N, Nordin S. Symptom-trigger factors other than allergens in asthma and allergy. Int J Environ Health Res. 2016;26(4):448-57.

29. Nuvolone D, Petri D, Voller F. The effects of ozone on human health. Environ Sci Pollut Res Int. 2018;25(9):8074-88.

30. Bell ML, Dominici F, Samet JM. A meta-analysis of time-series studies of ozone and mortality with comparison to the National Morbidity, mortality, and air pollution study. Epidemiology. 2005;16(4):436-45.

31. World Health Organization. Air quality guidelines global update 2005. Particulate matter, ozone, nitrogen dioxide and sulfur dioxide. Copenhagen, WHO Regional Office for Europe. (http://www.euro.who.int/_data/assets/ pdf_file/0005/78638/E90038.pdf) Accessed 18 Dec. 2017.

32. Horstman DH, Folinsbee LJ, Ives PJ, Abdul-Salaam S, McDonnell WF. Ozone concentration and pulmonary response relationships for 6.6-hour exposures with five hours of moderate exercise to $0.08,0.10$, and $0.12 \mathrm{ppm}$. Am Rev Respir Dis. 1990;142:1158-63.

33. Pope CA III, Dockery DW. Health effects of fine particulate air pollution: lines that connect. J Air Waste Manage Assoc. 2006;56:709-42.

34. Kashima S, Yorifuji T, Tsuda T, Eboshida A. Asian dust and daily all-cause or causespecific mortality in Western Japan. Occup Environ Med. 2012;69(12):908-15.

35. Kim HS, Kim DS, Kim H, Yi SM. Relationships between mortality and fine particles during Asian dust, smog-Asian dust, and smog days in Korea. Int J Environ Health Res. 2012;22(6):518-30.

36. Chan CC, Ng HC. A case-crossover analysis of Asian dust storms and mortality in the downwind areas using 14-year data in Taipei. Sci Total Environ. 2011:410-411:47-52.
37. Matsukawa R, Michikawa T, Ueda K, Nitta H, Kawasaki T, Tashiro H, Mohri M, Yamamoto Y. Desert dust is a risk factor for the incidence of acute myocardial infarction in Western Japan. Circ Cardiovasc Qual Outcomes. 2014;7:743-8.

38. Kamouchi M, Ueda K, Ago T, Nitta H, Kitazono T. The Fukuoka stroke registry investigators. Relationship between Asian dust and ischemic stroke. Stroke. 2012:43:3085-7.

39. Watanabe M, Noma H, Kurai J, Shimizu A, Sano H, Kato K, Mikami M, Ueda Y, Tatsukawa T, Ohga H, Yamasaki A, Igishi T, Kitano H, Shimizu E. Association of sand dust particles with pulmonary function and respiratory symptoms in adult patients with asthma in Western Japan using light detection and ranging: a panel study. Int J Environ Res Public Health. 2015:12:13038-52

40. Bhaskaran K, Hajat S, Haines A, Herrett E, Wilkinson P, Smeeth L. Effects of ambient temperature on the incidence of myocardial infarction. Heart. 2009:95:1760-9.

41. Ye X, Wolff R, Yu W, Vaneckova P, Pan X, Tong S. Ambient temperature and morbidity: a review of epidemiological evidence. Environ Health Perspect. 2012;120(1):19-28.

42. Aoyagi Y, Shephard RJ. Habitual physical activity and health in the elderly: the Nakanojo study. Geriatr Gerontol Int. 2010;10 (suppl. 1:S236-43.

43. Giorgini $P$, Rubenfire $M$, Das $R$, Gracik T, Wang L, Morishita M, Bard RL, Jackson EA, Fitzner CA, Ferri C, Brook RD. Higher fine particulate matter and temperature levels impair exercise capacity in cardiac patients. Heart. 2015;101:1293-301.

44. McGorry RW, Hsiang SM, Snook SH, Clanny EA, Young SL. Meteorological conditions and self-report of low back pain. Spine (Phila Pa 1976). 1998;23(19):2096-103.

45. Pienimaki T. Cold exposure and musculoskeletal disorders and diseases. A review. Int J Circumpolar Health. 2002;61:173-82.

46. Yamazaki S, Nitta H, Murakami Y, Fukuhara S. Association between ambient air pollution and health-related quality of life in Japan: ecological study. Int J Environ Health Res. 2005:15(5):383-91.

47. Yamazaki S, Nitta H, Fukuhara S. Association between exposure to ambient photochemical oxidants and the vitality or mental health domain of the health related quality of life. J Epidemiol Community Health. 2006:60(2):173-9.

Ready to submit your research? Choose BMC and benefit from:

- fast, convenient online submission

- thorough peer review by experienced researchers in your field

- rapid publication on acceptance

- support for research data, including large and complex data types

- gold Open Access which fosters wider collaboration and increased citations

- maximum visibility for your research: over $100 \mathrm{M}$ website views per year

At $\mathrm{BMC}$, research is always in progress.

Learn more biomedcentral.com/submissions 